\title{
Poesía española del Siglo de Oro y lieder románticos alemanes: recepción lírica y transformación musical de la imagen de España
}

\author{
Mercedes Comellas \\ Universidad de Sevilla \\ mcomella@us.es
}

Recepción: 03/10/2017, Aceptación: 02/04/2018, Publicación: 11/12/2018

\begin{abstract}
Resumen
Durante el siglo xix la musicalización de textos líricos españoles del Siglo de Oro en forma de lieder románticos por parte de compositores de habla alemana (Beethoven, Loewe, Schumann, Jensen, Brahms, entre otros) sirvió para la difusión de un imaginario español que fue transformándose progresivamente conforme avanzaba la centuria y cuya evolución es especialmente visible en la musicalización de los textos. La naturaleza de este intercambio, que afecta a dos artes y dos lenguas distintas y en el que interviene de forma decisiva la mediación de los traductores, demuestra de un lado la importancia de canales de trasmisión poco habituales en la difusión de textos literarios; de otro, que los mayores representantes del canon poético en el país de origen no fueron casi nunca los que tuvieron más éxito en las versiones del lied. Por otra parte, pareja a la moda musical española se generó una fórmula lírica que imitaba ciertos rasgos de la poesía castellana y se hacía pasar por tal en las versiones musicales de Weber, Mendelssohn o Schubert. La traslación de materiales literarios al arte musical implica una relectura profunda de la tradición poética, hasta el punto de sumar a la traición del traductor ('traduttore traditore') la del compositor.
\end{abstract}

\section{Palabras clave}

poesía española del Siglo de Oro; lieder románticos alemanes; traducción; imaginario; canon

\section{Abstract \\ Spanish Poetry of the Golden Age and German Romantic lieder: lyrical reception and musical transformation of the image of Spain \\ During the 19th century Spanish lyrical Golden Age texts were set to music as Romantic lieder by German-speaking composers (Beethoven, Loewe, Schumann, Jensen, Brahms,}


among others), a process that served to spread an imagery of Spain that underwent a gradual transformation as the century advanced, and whose evolution is particularly visible in the setting of the texts to music. The nature of this exchange, which affects two different arts and two different languages, and where the translators' mediation plays a decisive role, shows on one hand the importance of less habitual channels of transmission in the dissemination of literary texts; on the other, that the greatest representatives of the poetic canon of the country of origin were hardly ever the most successful in the lied versions. In addition, parallel to this Spanish fashion in music a lyrical formula sprang up that imitated certain features of Spanish poetry and in fact passed as such in musical versions by Weber, Mendelssohn or Schubert. Rendering literary materials into music implies a deep rereading of the poetic tradition, to the point that the translator's treason ('traduttore traditore') is compounded by the composer's.

\section{Keywords}

Spanish Golden Age poetry; German Romantic lieder; translation; national imagery; canon

Los estudios sobre la recepción de la literatura española en Alemania apenas se han detenido en la difusión musical de textos líricos españoles a través de los lieder románticos. ${ }^{1}$ Entre las escasas aportaciones deben mencionarse el interesante artículo de la musicóloga Sandra Myers, la panorámica de Gerardo Fernández San Emeterio y su posterior artículo sobre el Spanisches Liederspiel y las Spanische Liebeslieder de Robert Schumann, asunto también del trabajo de Aristegui y Seibold y de la tesis de Manuela Muñoz Martínez sobre Los ciclos españoles de Robert Schumann, a los que se suman el folleto de Sleeman y Davies sobre el Spanisches Liederbuch de Hugo Wolf y sus fuentes en la obra de Geibel y Heyse; por fin, Miguel Ángel Vega Cernuda hace un breve apunte sobre el lied romántico en su

1. Entiéndase «alemán» y «Alemania» referidos a una región lingüística y cultural, no unificada políticamente. 
artículo sobre la imagen española en Alemania a través de la ópera. ${ }^{2}$ De todos ellos me propongo partir para observar cómo esta forma de difusión incorporó canales de trasmisión poco conocidos y acompañó un cambio de imaginario de lo español en el territorio de habla alemana, especialmente visible en la musicalización que se hace de los textos.

Antes de comenzar el repaso del corpus es necesario apuntar algunos elementos contextuales que deben ser tenidos en cuenta. El primero de ellos, el extraordinario desarrollo del hispanismo alemán en la segunda mitad del siglo XviII, con primer núcleo significativo en el Leipziger Kreis de Abraham Gotthelf Kästner, Gotthold Ephraim Lessing y Johann Friedrich von Cronegk. Tuvo su continuación en los esfuerzos de Christian Gottlob Heyne desde la Universidad de Götingen por reunir una bien provista biblioteca de textos poéticos del Siglo de Oro y en la traducción en 1769 de Johann Andreas Dieze de los Orígenes de la poesía castellana de Velázquez. ${ }^{3}$ Por fin, la fundación en 1780 por Friedrich Justin Bertuch de la Magazin der spanischen und portugiesischen Literatur da fe de la difusión que llegaron a cobrar los estudios de hispanística. A pesar del trabajo de Lyte (1932) queda mucho por investigar sobre la recepción de textos españoles a través del amplísimo número de publicaciones periódicas (académicas o populares) que circulaban en Alemania en este periodo; y en particular no se ha estudiado la prensa musical, que también sirvió para la difusión de textos españoles de diferente naturaleza.

El avance del primer hispanismo coincide con la intensa asociación de España con la música: si para Herder la poesía española popular es una forma de canto, Friedrich Schlegel piensa que España es una «musikalische und zart dichtende Nation» (nación musical y dulcemente poética). ${ }^{4}$ El Romanticismo generalizó la convicción de que el alma española se expresaba a través de una música y de un ritmo particular. ${ }^{5}$ Todo ello resultaba especialmente relevante en el contexto de la teoría poético-musical que vino a imponer el ut musica poesis en las baladas, canciones y lieder, nuevos modelos líricos que frente al

2. Myers (2013), Fernández San Emeterio (1997) y (2005), Aristegui y Seibold (1981), Muñoz Martínez (2015), Sleeman y Davies (1982), Vega Cernuda (1999).

3. La colección de la universidad de Göttingen serviría a los estudios hispanísticos de Grimm, Bouterwek, Tieck y los Schlegel, después a Ticknor para componer su History of Spanish Literature (Boston-Londres, 1849) y a Heine, estudiante de la universidad hasta su expulsión, para componer su tragedia Almanzor, según dejan observar los registros de uso de la biblioteca. Kanowsky (1973: 129-153).

4. Briesemeister (2004: 466).

5. Ya a finales del siglo XVIII, las Letters from an English traveller in Spain, in 1778 de John T. Dillon (1781: 105) demuestran la difusión de la idea, que según él remite al más famoso musicólogo español del Renacimiento: «that the Spanish language is admirable adapted to poetic harmony, has been generally allowed, and has been evidently proved by an excellent judge, Francisco Salinas, of Burgos, born in 1513, celebrated by his contemporaries for his great skill in music, as a performer and a theorist». 
clasicismo y lo formal (la Kunstdichtung o poesía artística) dan la preferencia a la Naturdichtung (la poesía natural) y con ello a los textos anónimos generados por el pueblo. ${ }^{6}$ El modelo era España, que para Schlegel encarnaba un estadio mítico primigenio en el que música y poesía fueron inseparables. Sobre aquel hermanamiento musical en el origen de las lenguas había tratado Herder en trabajos de 1767 y 1770: Über die neuere deutsche Literatur y el Abhandlung über den Ursprung der Sprache, ${ }^{7}$ en los que imaginaba el lenguaje primitivo como una suerte de música, aun reconocible en los acentos musicales griegos y en otros usos tonales, ecos de la melodía natural oculta bajo la formalización lingüística. La primera etapa de las lenguas había sido un estado de naturaleza cantante de cuya fuerza musical surgieron los grandes vates como Homero, y a ella se podía volver integrándose el poeta en la lengua natural del pueblo (como ocurre en los romances cultos, según Herder). ${ }^{8}$

La idea de la España musical también coincide con la revalorización de los romances, que habían empezado ya a mediados del siglo XviII a difundirse por Europa y pronto se asocian al canto al considerarse la encarnación de la Naturpoesie. La traducción de Gleim en 1743 de tres romances de Góngora y sus propias imitaciones en alemán (Romanzen, 1756) desataron una fiebre de romances a la que contribuyó la traducción de Jacobi (Romanzen aus dem Spanischen des Gongora, 1767). Pero fue Herder uno de los primeros interesados en estudiar los romances como representación de la musicalidad intrínseca de la poesía espańola y valorarlos con los criterios de la nueva estética prerromántica. En su primer volumen de las Volkslieder de 1778 hay once romances españoles. ${ }^{9}$ Entre ellos algunos de Góngora traducidos por él mismo con no

6. En particular, Schlegel considera la poesía «eine geistige Musik» (una poesía espiritual): el principio del ritmo, el cómputo silábico, la rima, son elementos musicales, por lo que, consecuentemente, "viele musikalische Kompositionen [... seien] nur Übersetzungen des Gedichts in die Sprache der Musik» (muchas composiciones musicales son traducciones de poemas al lenguaje de la música). Schlegel (1962: II, 233 y 221). Joseph von Eichendorff y Achim von Arnim desarrollan una Grundmelodie-Metaphorik que el primero expone en la Geschichte der poetischen Literatur Deutschlands: la música es «Seele der Lyrik» (alma de la lírica), pues le proporciona su emocionalidad y subjetividad. Eichendorff (1993: IX, 96 y 154); Steinig (2006: 155). Un resumen de la teoría musical del Romanticismo en Comellas («Tras los límites del lenguaje»).

7. Herder (1767: 73-74) y (1770: 141-142).

8. Algunas de estas ideas debieron llegar a España y pueden observarse en las polémicas que sobre la función de las reglas enfrentaron a finales de siglo a distintos partidos musicales en el Diario de Madrid. De Persia (1991: 310-311). Especialmente son visibles en los seguidores del jesuita exiliado Antonio Eximeno, cuyos argumentos remiten a la idea del origen musical de las lenguas, que van preparando el terreno a los criterios nacionalistas de los románticos. De hecho, resulta muy interesante comparar estas polémicas con la que pocos años después enfrentará a Böhl de Faber y José Joaquín de Mora en el terreno literario, pues ambas comparten muchos puntos en común. 9. Los textos españoles que se recogen son algunos romances de Góngora, del cancionero de Amberes y de las Guerras civiles de Granada. Según recuerda Leonardo Romero (2012: 14), «Herder amplió su lectura del romancero en la frecuentación de romances cidianos en la traducción francesa de la Bibliothèque des romans". 
poca dificultad, pues «Góngora Deutsch zu geben, ganz wie er ist, müßte man selbst Góngora sein» («para traducir a Góngora sin traicionarlo, habría que ser Góngora mismo»). ${ }^{10}$ Herder explica la inclusión de autores cultos en la colección, también en el caso de Shakespeare o del propio Goethe, como demostración de las posibilidades que estos tienen de componer poesía "popular» y sumarse así a la voz de su pueblo. ${ }^{11} \mathrm{La}$ idea tuvo considerable éxito y así se lo propusieron Eichendorff, que asimiló la forma del romance en sus Lieder, o Heinrich Heine, que incluye también romances en el Buch der Lieder. ${ }^{12}$

La recurrencia a modelos populares por parte de autores cultos es una tendencia que del terreno poético se trasladará al musical, como veremos en los mismos lieder, y que remite a un modelo nacionalista y una nueva concepción expresiva y orgánica del objeto artístico. Se entendía que los cantares populares hacían posible la expresión de un sentimiento aparentemente inefable y que la expresión colectiva, popular, era capaz en su anonimia de trasladar a verbo gracias a recursos expresivos genéticamente unidos a sus orígenes musicales. De ahí que los autores cultos practiquen lo que podría calificarse como un falso cantar popular, imitando ciertos recursos que lo hacen especialmente adecuado a la musicalización en lied, como los esquemas poéticos de la repetición, los fáciles juegos rítmicos, los paralelismos o el diálogo.

El contexto brevemente presentado muestra la importante presencia de lo español y de sus textos en el paisaje cultural de los estrenos románticos. Schöning ha comprobado en este sentido la significativa abundancia de traducciones de textos literarios españoles al alemán, con porcentajes que dejan clara la preeminencia sobre otras literaturas extranjeras; ${ }^{13}$ particularmente se prefieren los llamados «alte Volkslieder» o romances viejos, a los que siguen los autores del Siglo de Oro, entre los que Cervantes, Calderón, Lope, Rioja, Villegas, Ercilla, Quevedo, Tirso, Boscán, Herrera y Góngora tienen posiciones señaladas. España se ha constituido como nuevo modelo al tiempo que sobre

10. Herder (1778: 233). Traducción mía.

11. Sleeman y Davies (1982: 160-161). Herder entiende que la poesía popular tiene una capacidad pedagógica, con cuya ayuda podemos acercarnos a la forma de vida positiva y original, auténtica. Steinig (2006: 163-4). Además, para Herder el español es casi una lengua sagrada y religiosa ("fast heilige Kirchensprache»). Briesemeister (2004: 60). Para Herder, las canciones populares nos traen la "Stimme der Menschheit», del ser humano tal como Dios lo creó y lo quiso, estableciendo así una correlación entre la empatía humana y la poeticidad natural, que será lugar común de los románticos: esa voz original y primera del hombres, común a todos a través de la música, es la que nos permite encontrarnos y comunicarnos unos con otros.

12. Las fuentes de Eichendorff para sus imitaciones de romances fueron principalmente la Silva de romances viejos de Jacob Grimm (1815) y el Teatro pequeño de elocuencia y poesía castellana de Victor Aimé Huber (1832). Heine incluye en su colección veinte romances que imitan con algo de actitud paródica el tono lírico-épico de los españoles e incorporan su personal ironía a través de la inclusión de elementos autobiográficos.

13. Schöning (1996: 415). 
ella se construye un imaginario exótico que también será útil a los intentos de renovación musicales.

El propio género del lied es una novedad en la tradición de la música culta; podría interpretarse como un experimento artístico con el que se buscaba volver a conectar la palabra poética con su original fuerza sonora. Enlaza con el interés en la música popular y no en vano el surgimiento de las primeras escuelas de lied en Viena y Berlín coincide con la publicación de las Stimmen der Völker in Liedern de Herder (título que se dio a la segunda edición en 1807 de los Volkslieder de 1778) y la nueva poética musical. Entre los primeros compositores del género están también los grandes renovadores musicales: Mozart, Haydn y Beethoven; los dos últimos inician la tradición de los ciclos de lieder agrupados como canciones populares de distintas nacionalidades: escocesas, irlandesas; ${ }^{14}$ después llegarán los ciclos españoles.

Los primeros lieder supeditan la música (que actúa como mero soporte) a la poesía: la música genera simplemente la atmósfera y la palabra trasmite la idea, de ahí que los acompañamientos pianísticos sean al principio muy sencillos. Después, con la evolución del género, la música irá ganando en importancia y cobrando mayor protagonismo, hasta equipararse a la poesía. ${ }^{15}$ Schubert marca el cambio al transformar el carácter del lied y la relación entre música y poesía; a partir de Schumann la música domina sobre el poema y las palabras se entregan a la melodía. El compositor puede permitirse malinterpretar al poeta, lo que, como veremos, tendrá importancia en el tratamiento musical de los textos españoles.

\section{Primer repertorio}

El repertorio de lieder con textos españoles del Siglo de Oro puede iniciarse con la actriz y cantante alemana Corona Schröter, protegida de Goethe en Weimar, que su colección de 25 lieder para voz y piano de 1786 incluyó el romance español de Góngora "Que se nos va la Pascua, Moças», traducido por Herder en Stimmen der Völker ("Frühling währt nicht immer, Mädchen») de forma bastante libre. ${ }^{16}$ El poeta cordobés ya había conocido versiones musicales de su obra: el Polifemo fue llevado a la zarzuela por Antonio Linares en 1709 y el mismo asunto polifémico a la ópera por Händel, primero en la cantata dramática de 1708 Aci, Galatea y Polifemo (HWV 72) y después en Acis y Galatea (HWV 49),

14. Recuérdese al respecto el impacto del ciclo ossiánico: la moda escocesa que inundó Europa, casi contemporánea a la de los romances, también tuvo expresión musical y contribuyó a la conformación de nuevas formas líricas, como las baladas.

15. Bingham (2004: 102).

16. No 6 de los Fünf und Zwanzig Lieder. In Musik gesezt von Corona Schröter. Myers (2013: 7-9). El romance de Góngora que versiona Schröter había aparecido en el segundo volumen del Stimmen der Völker de Herder, que anota: «Aus Góngora Romances líricos». 
con libreto de John Gay, compuesta probablemente en 1718 y la más popular de las obras dramático-musicales de Händel en su época, hasta el punto de que conoció una nueva orquestación de Mozart en $1788 .{ }^{17}$

El romance que elige Schröter concuerda con el talante burlesco que por influencia francesa se había valorado particularmente en los originales españoles desde el segundo tercio del XviII. El carácter festivo y sensual lo hace adecuado al gusto de finales de la Ilustración, que es el que también le acompaña musicalmente: «Las palabras de Góngora, al igual que las de Shakespeare, eran consideradas como universales, y fueron tratadas en lenguajes musicales universales». ${ }^{18} \mathrm{~A}$ Schröter aún no le interesa el exotismo de lo "español», que todavía no ha llegado a configurar un imaginario artístico concreto. Este irá apareciendo en otras versiones musicales posteriores del romance, que las tuvo de Johann Friedrich Hugo von Dalberg, Wilhelm Albert Rischbieter, Arnold Mendelssohn y Robert Kahn (muchas veces con el título que Herder dio al romance en su traducción: «Der kurze Frühling»).

La primera de ellas corresponde también al periodo estudiado, pues Dalberg, uno de los primeros musicólogos alemanes, compositor de música de cámara y piezas para piano, estuvo muy interesado en el lied, uno de los géneros que más practicó en su obra creativa, probablemente influido por las teorías de Herder, de las que hay evidente presencia en sus escritos estéticos y musicales. Quizá llegó a interesarse por Góngora en la Universidad de Göttingen donde estudió y a cuya Akademie der Wissenschaften pertenecería; a esa formación y contactos académicos también puede atribuirse su interés general por España y por la música oriental (en aquellos años en los que España era considerada el Oriente de Europa). Sin embargo, su dominio musical sigue siendo el clasicismo de Viena, aunque ya en los lieder españoles asoma cierto énfasis que adelanta los gustos románticos.

Góngora fue así el primer poeta del Siglo de Oro que conoció musicalización en lied a partir de la traducción de Herder de sus romances, a su vez continuación del interés que propiciaron Gleim y Jacobi al difundir su obra romanceril en lengua alemana. Porque a diferencia del Góngora que interesó a las composiciones musicales dieciochescas, que es el culto y mitológico, lo que ahora se musicaliza en los inicios del género son los romances, por su conexión con las formas de la poesía popular.

También la tiene un segundo lied español que compuso Dalberg, «Die Echo», a partir de otra traducción de Herder también incluida en Stimmen der Völker, donde versiona libremente la canción «Contando está Melibeo / a Florisa su dolor» del libro V de la Diana enamorada de Gil Polo. Según anota el propio Herder — que sigue la edición de Londres (1739) y el Parnaso Español de López

17. No se han investigado las fuentes literarias del libreto de Gay ni el posible papel entre ellas del texto gongorino.

18. Myers (2013: 9). 
de Sedano- es glosa de un romance que termina con los versos: «ella responde: pastor / ni te entiendo, ni te creo». Tanto el ambiente pastoril en el locus amoenus que recrea brevemente Herder en los primeros versos, como la terneza de la escena remiten de nuevo al sensualismo de finales de la Ilustración, pero ya asociado al gusto por los cantares sencillos de inspiración popular. En este sentido, la repetición del estribillo (los versos glosados en el original, únicos que respeta Herder fielmente en su traducción) hace al poema especialmente adaptable a la musicalización en lied. Como en los casos anteriores, para acompañar los versos no se busca una melodía «española».

Esta se incorporará con la llegada del Romanticismo musical en la obra de Beethoven y el primer interés por trasladar el elemento exótico a los lieder. En consonancia, los textos que elige el compositor de Bonn no son los de Góngora ni Gil Polo, que remiten a los gustos aun asociados al sentimentalismo o sensualismo dieciochesco, sino otros que corresponden a un imaginario español de nuevas connotaciones.

Beethoven demostró ya su interés por el escenario español en la ópera Fidelio, ubicada en Sevilla y en la que no se ocultan los nuevos valores políticos, o $L a$ victoria de Wellington, obra orquestal (muy popular en su época) que ya da pistas de la fascinación por la España de la Guerra de la Independencia en cuanto escenario de movimientos de renovación política y demostración de los nuevos ideales de libertad. En ella llama la atención la inclusión de un tema popular español, Mambrú se fue a la guerra. ${ }^{19}$ Cuando el editor escocés George Thomson le pidió que compusiera música para aires escoceses, galeses e irlandeses (los Lieder verschiedener Völker o 23 canciones de diversos países, escritas entre 1815 y 1816 para voz y piano), incluyó cuatro canciones también basadas en textos populares espańoles y que además intentan trasladar elementos de la musicalidad del país. ${ }^{20}$ Otra singularidad es que se mantiene el original español de los textos, sacados de fuentes muy peculiares. Tres de ellos proceden de la Colección de las mejores Coplas de Seguidillas, Tiranas y Polos, que se han compuesto para cantar a la guitarra con un discurso sobre las causas de la corrupción y abatimiento de la música Española (1799), reunidos por el proto-folclorista Juan Antonio de Iza Zamácola (Don Preciso) en un volumen que debió tener una difusión importante en tierras alemanas (en España conoció seis ediciones hasta 1816), ${ }^{21}$ pues servirá a otros lieder y a colecciones de traducciones de versos populares españoles.

Precisamente Iza Zamácola se dio a conocer como ferviente hispanófilo y ácido crítico de las modas afrancesadas en música y bailes de los llamados cu-

19. En 1785 se estrena tonadilla escénica «La cantada vida y muerte del general Malbrú», que incluye un ejemplo de tirana, nuevo género de baile y canto de moda en la segunda mitad del XviII al que Goya afirma, en carta a su amigo Zapater, ser muy aficionado. García-Matos (1981: 302).

20. Alcalde (1997: 1-2). No se publicarían hasta 1940 en las Canciones de distintos pueblos, WoO 158. 21. García-Matos (1981: 299). 
rrutacos (a pesar de que colaboraría con el gobierno de José I), para defender con criterios prenacionalistas nuestra propia tradición musical. También en los prólogos a sus dos volúmenes se observa la influencia de Herder, cuando afirma, por ejemplo, que la música es auxiliar de la poesía y del baile, a las que va unida, o al sostener que «nace con nosotros y obra efectos según las costumbres de las diferentes naciones y la índole de su lenguaje sobre cuya poesía se compone; así se ha visto que todos los pueblos del mundo, desde los más bárbaros hasta los más civilizados, han tenido y tienen un género de música propio o nacional para explicar sus pasiones». ${ }^{22}$

La seguidilla y sus variantes para la danza (boleros y tiranas) son para Don Preciso "propiamente hablando, nuestra poesía lírica», ${ }^{23}$ la que «explica» las pasiones españolas. Y son estos géneros los que Beethoven adapta a sus lieder españoles: las seguidillas «Ya no quiero embarcarme», dos boleros («Una paloma blanca» $\mathrm{y}$ "Como la mariposa soy») y "La Tirana». El texto de esta última, único que no se encuentra en la Colección de Zamácola, se había publicado en el Allgemeine Musikalische Zeitung de Leipzig (1799), incluido en el artículo «Etwas über den jetzigen Zustand der Musik in Spanien» («Sobre el estado actual de la música en España»). ${ }^{24} \mathrm{El}$ autor comienza explicando que su ensayo responde al interés en la música española por su característica más acusada: la originalidad, que se demuestra no tanto en la música culta como en la popular. De ella hace una descripción que probablemente sea el primer intento de explicar al público de lengua alemana los cantes flamencos. ${ }^{25}$ Acaba afirmando que las canciones nacionales españolas son extraordinarias: un canto de una fuerza extraña, que genera emociones intensas, capaces de transmitir una expresividad que jamás puede encontrarse en las cultas óperas italianas, alemanas o francesas.

Esa misma expresividad es la que debió interesar a Beethoven en sus lieder españoles: no solo las letras se mantienen, como se ha señalado, en la lengua original, sino que también se trasladan con energía las melodías españolas. El bolero, de moda ya en toda Europa, trasmitía la imagen de una España bizarra y violenta a la que contribuyó la extraordinaria fama internacional que conquistó la canción de Manuel García «El contrabandista» — de su ópera El poeta calculista-, que incluso llegaría a servir como canción patriótica de resistencia al francés. ${ }^{26}$ Motivos populares en textos y música encarnan ideales políticos de libertad: la misma que busca la música de Beethoven. Recuérdese que ya Kant había asociado al talante español la manera de lo sublime terrorífico y así en las Observaciones acerca del sentimiento de lo bello y de lo sublime asegura que en el

22. Iza Zamácola (1799: I y XXVII).

23. Iza Zamácola (1799: XLV).

24. Carreira se refiere al interés de esta publicación, en la que las noticias sobre música española son abundantes, sin que sin embargo haya recibido el estudio que merece (1998: 16).

25. El interés del artículo merece un estudio aparte que me propongo publicar en breve.

26. Parakilas (1998: 141). 
carácter español «se halla poca dulzura y benevolencia», pues «es muchas veces duro y aun cruel», de "gusto extravagante»: «no se puede decir que los españoles sean magnánimos o más amorosos que ningún otro pueblo, pero son lo uno y lo otro de una manera bizarra e inusitada». ${ }^{27}$

Lo español va generando una manera literaria que ciertos poetas quisieron imitar y que desde Schlegel, Uhland, o Brentano muchos románticos sintieron que conectaba directamente con el acervo popular alemán. ${ }^{28}$ De ahí que habitualmente en los programas musicales se hayan presentado como españolas varias obras de Carl Maria von Weber, Felix Mendelssohn o Franz Schubert, cuando en realidad los textos sobre los que compusieron sus lieder no son originalmente españoles, sino versiones o imitaciones de motivos con los que se fue generando un particular imaginario espańol, asociado a los valores de temperamento, emoción sencilla e ironía. Así por ejemplo ocurrió con la moda cervantina, en cuyo contexto escribió Weber las musicalizaciones en forma de canción para el Schauspiel titulado Preciosa (1821), sobre la versión que Pius Alexander Wolff había escrito de La gitanilla; aunque los textos se suelen atribuir en los programas a Cervantes, no son en ningún caso traducciones directas, sino adaptaciones muy libres del texto cervantino.

La novela ejemplar tuvo varias versiones operísticas en el siglo XIX y su argumento era conocido para el público europeo, como también «las bodas de Camacho", el episodio cervantino más fecundo en versiones musicales ${ }^{29}$ y asunto de la ópera cómica de Mendelssohn Die Hochzeit des Camacho (op. 10, 1825), compuesta en años de juventud (el compositor llegó a considerarla «su pecado juvenil»), estrenada tardíamente y sin ningún éxito. El libretista, Karl Klingemann, es también autor del supuesto romance español anónimo que se incluye en el repertorio de Mendelssohn («Romanze: Einmal aus seinen Blicken», 18241828). El título del lied demuestra la difusión del término "Romanze» para referirse a canciones líricas y sentimentales, asociadas a la moda popularista que tenía a lo español como referente.

Tampoco Schubert usa textos originalmente españoles en sus muchos $-\mathrm{y}$ extraordinarios- ciclos de lieder, con los que abrió una nueva etapa en la evolución del género al equiparar el papel del piano con el de la voz: música y palabra sintonizan y se corresponden en un diálogo que no somete a ninguna de las dos, sino que hace ganar significado a ambas en su interconexión.

El interés por lo español se observa desde sus obras juveniles, como en el estupendo ciclo Don Gayseros (D 93, ca. 1815) sobre textos de La Motte Fouqué, traductor de Calderón y autor de una de las novelas más exitosas del romanticismo alemán, Der Zauberring, ficción caballeresco-fantástica llena de aventuras

27. Kant (1990: 29).

28. Sleeman y Davies (1982: 181).

29. Vega Cernuda (1999: 323). 
mágicas y exóticas. Uno de los personajes, el español Don Hernandez, canta esos versos sobre el caballero Don Gayseros (el Gaiferos de los romances españoles y del retablo de Maese Pedro) que sirvieron a Schubert para estos tempranos lieder — de atribución discutida-.${ }^{30}$ Como en el caso de Weber o Mendelssohn, no estamos ante traducciones de originales españoles, sino ante obras de asunto español que quieren imitar la manera lírica española al tiempo que tratan de trasladar con acordes sincopados el sonido de la guitarra. Lo mismo ocurre con sus llamados lieder españoles, dos de ellos poemas del mismo Zauberring de La Motte Fouqué («Nächtens klang die süsse Laute», D.93/2 y «An dem jungen Morgenhimmel», D.93/3) y el tercero sacado de Diego Manzanares, novela de su amigo Franz Xaver Schlechta; los textos no son de origen español, pero buscan el tipismo de las baladas españolas.

Así que el interés de Schubert por lo español, o su tributo a la moda española, se conformó con creaciones alemanas que imitaban aquellas claves líricas. Lo mismo ocurre con sus óperas, asunto que queda al margen del marco de este estudio, pero que vale mencionar para confirmar este uso alemán de lo español: el Singspiel de dos actos Die Freunde von Salamanka (1815) está compuesto sobre un texto de su amigo Johann Baptist Mayrhofer inspirado en el teatro popular y que remite musicalmente al Beethoven interesado en la España bizarra y sus melodías populares. Diego y Fidelio son los amigos salmantinos que sirven a una imagen ingenua y tópica de Espańa: bandidos, alcaldes, escenas campestres, motivos cómicos y costumbrismo. ${ }^{31}$

También su ópera Alfonso und Estrella (intento de renovar la gran ópera romántica separándose del Singspiel) tiene tema español. Se compuso sobre libreto en verso de su amigo Franz Adolf Friedrich Schober, que pudo inspirarse en alguna obra dramática española (quizá en Las desgracias del rey don Alfonso el Casto de Mira de Amescua) o sacarla de cualquiera de los almanaques noticiosos y recopilaciones tan difundidas por las imprentas alemanas. ${ }^{32}$

El ciclo español de Carl Loewe (los Spanische Romanzen) sí remite en parte a textos originales españoles, como en el caso de "Der Sturm von Alhama» (op. 54, 1835), traducción de Victor Aimé Huber del romance «Paseábase el rey moro" incluida en los Skizzen aus Spanien (1828) con el título de "Gar klägliche Romanze von dem Sturm und der Einnahme von Alhama». Curiosamente el poema había ya conocido versión musical para acompañamiento de vihuela de Luys de Narváez (Los seys libros del Delphin de música de cifras para tañer vihuela,

30. Einstein (1986: 69).

31. «La España ignota se convertía en un locus amoenus, en una arcadia idílica [...]. Así la rústica canción castellana se hacía lied schubertiano, la dehesa charra bosque frondoso [...] y la vida campesina no era sino juegos, bromas y cantos». Vega Cernuda (1999: 355-357).

32. No hay ningún estudio sobre las fuentes españolas de estas obras schubertianas y mis primeras pesquisas no me han permitido todavía llegar a conclusiones definitivas. Espero poder desarrollar en trabajos ulteriores algunas hipótesis sobre el tejido de textos en los que se basó Schober. 
$1538)^{33}$. En el XIX tuvo una difusión importante y muchas traducciones, entre ellas la de Herder en los Volkslieder y la de Byron. La moda del imaginario oriental asociado a España favoreció el éxito del lied de Loewe, que intenta (con solo medianos resultados) reunir la emoción épica con el dramatismo de la derrota en una composición de muy marcado ritmo.

Este es el único de los spanische Lieder de Loewe compuesto sobre una traducción del original español. No ocurre lo mismo con las demás composiciones de este músico aficionado a la poesía popular: la balada «Die Gruft der Liebenden» (1832), que Loewe pensaba anónima española, era versión alemana de un asunto español (Pedro, rey de Castilla tenía que casarse con la hija del rey García, que toma un bebedizo para hacerse creer muerta y acabar sin embargo fatalmente falleciendo). ${ }^{34}$ También "Donna Anna", de Balladen und Romanzen (1841), parte de un texto de Johann Nepomuk Vogl, y el lied «Täglich ging die wunderschöne» (Der Asra, op. 133) es uno de los Spanishe Romanzen de Heine. Particularmente curioso es el caso de su lied «Zumalacarregui, Spanische Romanze», compuesto por Loewe a sugerencia del Príncipe Friedrich Wilhelm de Prusia en 1837 e incluido en Hohenzollern-Balladen-und-Lieder.

De nuevo, como en el caso de Schubert, el ciclo de los Spanische Romanzen y todos los demás lieder españoles de Loewe no tienen como base, salvo en el romance de Alhama, textos españoles (aunque así lo creyera incluso el propio compositor), sino poemas de autores alemanes que imitan los modelos españoles.

\section{El papel de las antologías: Geibel, Heyse y Diepenbrock}

Esta tendencia cambia a partir de una colección fundamental para la difusión musical de obras poéticas espańolas: Volkslieder und Romanzen der Spanier (1843) de Emanuel Geibel, uno de los poetas más populares de su tiempo (su primera antología de 1840 tuvo cien ediciones) y también uno de los más trasladados a música del siglo XIX, solo por detrás de Heine. ${ }^{35}$ Conocía muy bien la literatura española desde sus estudios en Lübeck, continuados en la biblioteca del caballero Karl von der Malsburg (hermano de Otto von der Malsburg, el traductor de Calderón de la Barca y Lope de Vega), que contaba con una importante colección española; mientras trabajaba en su ordenación durante el año de 1841-42, aprovechó para estudiar el Romancero y preparar su Volkslieder und Romanzen der Spanier con ayuda de Huber. ${ }^{36}$ Se sirvió para la colección del Cancionero de romances (Amberes, 1555), el Romancero general (Madrid, 1604),

33. Versión de Capella de Ministrers en <https://www.youtube.com/watch?v=49FuFha0KHg>. 34. El tema fue también tratado por Vogl en las Balladen de 1837 con el título de «Der Grabeswächter».

35. Sleeman y Davies (1982: 164).

36. Sleeman y Davies (1982: 165). 
la Silva de romances viejos de Jacobo Grimm (Viena, 1815), la Floresta de Böhl, el Teatro pequeño de Huber (Bremen, 1832), el Tesoro de los romanceros y cancioneros españoles, de Eugenio de Ochoa (París, 1838), y en menor medida de la Sammlung der besten alten spanischen historischen Ritter- und maurischen Romanzen de Depping (Leipzig, 1817), la Colección de las mejores coplas de seguidillas, tiranas y polos de Zamácola y The Zincali, or an account oft the Gypsies of Spain with an original collection of their songs and poetry de George Borrow (London, 1841). De entre todas ellas, la Floresta se demuestra la fuente de al menos dos terceras partes de los poemas traducidos, de manera que puede afirmarse que, gracias a Geibel y sus Volkslieder und Romanzen der Spanier, la recopilación de Böhl von Faber (especialmente el primer volumen, donde se concentra la poesía popular) conoció una segunda vida poética en Alemania, y sobre todo musical. ${ }^{37}$ Lo mismo le sucedió a otra de sus fuentes: Flor de Enamorados (Barcelona, 1562), muchos de cuyos poemas, casi desconocidos en España por aquellas fechas, se difundieron gracias a las traducciones de Geibel y Heyse. ${ }^{38}$

Las posiciones conservadoras de Geibel, continuador de la segunda escuela romántica de Chamisso, Eichendorff y Holtei (todos ellos imitadores de las fórmulas líricas populares españolas), le llevarían hasta Munich, adonde fue invitado en 1852 por el rey Maximiliano II de Baviera. Allí se convirtió en el líder del grupo de poetas Der Krokodil, tradicionalistas y contrarios al movimiento de la Joven Alemania y al Realismo poético. En el mismo grupo participaba Paul Heyse, con quien Geibel publicó la estupenda colección Spanisches Liederbuch, preparada mientras ambos sostenían un importante contacto con el mejor hispanismo alemán. ${ }^{39}$ La obra tuvo una difusión musical extraordinaria: más de cien de aquellas traducciones de poemas españoles conocieron versiones musicales (incluyendo textos del Arcipreste de Hita o la Celestina), a veces en varias ocasiones: el Cantarcillo de la Virgen, de Lope, traducido como «Die ihr schwebet», tuvo seis versiones distintas, entre ellas las de Brahms (de la que se tratará después), Gustav Flügel o Friedrich Gernsheim.

En las traducciones de Geibel y Heyse y las versiones musicales para lieder de aquella colección se observa un importante cambio de actitud hacia la tradición española: si las primeras imágenes musicales de España valían para conectar con el espíritu revolucionario y la ruptura con los moldes clásicos, tanto políticos como estéticos, en esta segunda fase de la recepción el repertorio español está asociado al talante conservador del Biedermeier, casi a la manera con que en los mismos años se vive en España la recuperación de la tradición popular de manos de un puñado de poetas conservadores que prepararon el camino de Bécquer. Como en

37. Molina Huete (2010: 289-326) hace un brillante estudio de la recepción española que tuvo la compilación, editada recientemente por ella misma: véase Böhl de Faber (2015).

38. Sleeman y Davies (1982: 170-173).

39. Sleeman y Davies (1982: 168). 
la estética becqueriana, los nuevos lieder españoles destacan lo suave, delicado y sugerente; se eligen poemas de estampas interioristas, que se musicalizan en tonos de melancolía y nostalgia. Las melodías corresponden a ese ambiente de salón familiar donde se interpretaban las canciones, un espacio privado que sirve de refugio al agotamiento revolucionario, ahora mansamente domesticado. Las piezas líricas se escogen para adaptarse a esta musicalización en tono menor. La imagen de España y de su poesía ha cambiado. A ello han contribuido las prolongaciones del romanticismo de la escuela de Brentano y Von Arnim hacia posiciones religiosas de intenso catolicismo. La defensa de los valores cristianos conservadores se asocia al mundo caballeresco español y a una Edad Media coloreada de suaves tonos neogóticos, la misma que traslucían las versiones de Geibel y Heyse, base de casi todos los nuevos lieder españoles del último periodo romántico.

Por otra parte, la apropiación de la «manera espańola» continúa en las colecciones de Geibel, hasta el punto de que consiguió hacer pasar por originales españoles poemas propios. ${ }^{40}$ Es el caso de "Nelken wind' ich und Jasmin", que atribuye a un tal Don Manuel del Río y que fue musicalizado, antes que por Schumann, por Niels Wilhelm Gade como «Spanisches Lied» (Lieder im Volkston, op. 9, 1845), Wilhelm Herzberg (Sechs Lieder, op. 6, 1846), Adolph Bernhard Marx (Spanische Lieder, op. 22, 1847) y años después por Friedrich August Naubert (Spanische Liebeslieder, 1876).

La primera colección de Geibel (Volkslieder und Romanzen der Spanier) sirvió a Adolph Bernhard Marx para su ciclo de lieder españoles de 1847. Compañero de estudios de Loewe y amigo de Mendelssohn — hasta su ruptura en 1841 - en el caso de Marx, y gracias a la importante difusión de las traducciones de Geibel, las canciones sí remiten a poemas originales castellanos, algunos anónimos y otros de autores conocidos (Castillejo, Pedro de Padilla, Comendador Escrivá, Antonio de Villegas...). Sin embargo, su obra musical, a diferencia de sus escritos teóricos, no tuvo el éxito que sí alcanzaron otros ciclos españoles basados también en las traducciones de Geibel: los de Robert Schumann. Con él, el género del lied vive un momento culminante. Si Schubert equipara el papel del piano al de la voz, Schumann los integra en una unidad tan íntima que ninguno puede subsistir sin el otro. ${ }^{41} \mathrm{Y}$ conforme la música va adquiriendo protagonismo, el tratamiento de «lo español» pierde el carácter nacional para integrar los textos en la tradición musical alemana.

La afición española de Schumann supera la de cualquiera de los otros autores mencionados: sabemos por su epistolario y diarios que llegó a estudiar la lengua y leer a Calderón. En su llamado «año español» (1849) compuso dos ciclos de canciones: Spanisches Liederspiel (op. 74) y Spanische Liebeslieder (op. 138 ), donde trata de crear un ciclo representable con varias voces. Las dos co-

40. Brinkmann (1975: 48 y 53); Sleeman y Davies (1982: 177).

41. Demmler (2010: 72). 
lecciones son fundamentales para la tradición del lied español. Primero porque, a pesar de algunos lieder de la serie gitana de Geibel (los Zigeunerliedchen), sus versiones sonaban ya lejanas al bolero, las castañuelas, la España salvaje y alegre de años anteriores (de hecho, para recordarnos que se trataba de un ciclo español decidió cerrarlo con una versión de «El contrabandista», la única canción que no corresponde a la tradición del Siglo de Oro y también la que más se acerca a aquel imaginario musical bizarro y exótico). ${ }^{42}$ Pero también porque no pocos de sus temas lograron difundir textos poéticos que conocieron versiones musicales posteriores de otros compositores. Esto es: la música, más que el texto en sí, los promocionó para su posterior difusión musical. Así, por ejemplo, él fue el primero en componer sobre textos de Gil Vicente los lieder: «O, schläfst du, mein Mädchen» («Si dormís, doncella»), «O wie lieblich ist das Mädchen» («Muy graciosa es la doncella») y "Von dem Rosenbusch, o Mutter» («Del rosal vengo, mi madre»), recogidos originalmente en la Floresta de rimas antiguas castellanas (1821-1825) de Böhl de Faber. Este último texto, por ejemplo, tuvo versiones de Max Bruch (en Vier weltliche Lieder aus dem Spanischen und Italienischen von E. Geibel und P. Heyse, 1864), Reinhold Ludwig Herman (Drei Lieder, 1894), Friedrich August Naubert («Von den Rosen komm’ ich», op. 4 de los Spanische Liebeslieder, 1876) o Leopol Damrosch (1903).

Otro caso llamativo es el poema «Alguna vez, / oh pensamiento» de Cristóbal de Castillejo, también incluido en la Floresta y que tras ser musicado por Marx («Dereinst») y Schumann («Liebesgram: Dereinst, o Gedanke mein») conoció versiones de Joseph Brambach, Friedrich August Naubert, Felix von Woyrsch, Leopold Damrosch, Freiherr von Bach, Edvard Grieg, Adolf Jensen, Henning Karl Adam von Koss, Heinrich von Sahr, Emil Sjögren, Hugo Wolf o Carl Banck. Así pues, un poema de Castillejo parece ser el texto lírico español más versionado musicalmente en lengua alemana gracias a la difusión de que gozó a través de la conmovedora versión musical de Schumann.

«Dereinst, o Gedanke mein» también tiene versión de Adolf Jensen, al que en su tiempo se consideró uno de los continuadores de Schumann. Amigo de Brahms, fue compositor sobre todo de música para salón, con ciento setenta y seis lieder. Entre sus ciclos hay dos españoles (op. 4 y op. 21) que compuso también sobre las traducciones del Spanisches Liederbuch, de ahí el título: Sieben Gesänge aus dem spanischen Liederbuche von E. Geibel und P. Heyse (1860). Incluyen una versión del poema de Lope de Vega «Madre, unos ojuelos vi», traducido en este caso por Heyse en el Spanisches Liederbuch como «Mutter, ich hab' zwei Äugelein», que aprovecha la repetición de los versos "iAy, que me muero por ellos, / Y ellos se burlan de mí!» para crear un estribillo musical: «Ach, um sie muß ich vergehen, / und die Augen spotten mein!». Sin embargo, en las melodías de Jensen para las canciones españolas no asoman apenas, como ya ocurría

42. Según Fernández San Emeterio (2005: 189). 
en las de Schumann, elementos que remitan al imaginario exótico musical de lo español. Siguiendo la línea de Schubert y Schumann, Jensen elige la emoción y la expresividad para unos textos que han pasado ya de sentirse folclore exótico para integrarse en la propia tradición alemana. Algo queda sin embargo de aquel origen, por ejemplo en su versión del romance «Tango vos, el mi pandero», recogido en la Floresta del Cancionero General (Lisboa, 1517) y traducido por Geibel entre los poemas gitanos como "Klinge, klinge mein Pandero». ${ }^{43} \mathrm{El}$ incipit de la melodía antigua del romance aparece en el De Musica Libri Septem de Francisco de Salinas de 1577, así que estamos ante un caso singular de popularidad que alcanza la tradición romántica: su traducción tuvo mucho éxito y conoció, además de la versión de Jensen, las de Niels Wilhelm Gade (1845) Adolph Bernhard Marx (1847), Heinrich von Sahr (1855), Franz Paul Lachner (1861), Hans Michael Schletterer (1864), Anton Rubinstein (1867), Friedrich August Naubert (1876), Heinrich Molbe (1879), Hugo Wolf (1889-1990) y otros, siendo otro de los poemas españoles del Siglo de Oro con más versiones musicales.

El mismo Lachner, amigo y compañero de Schubert y, como él, autor de cientos de lieder, tiene, además de su correspondiente versión de «Klinge, klinge mein Pandero", otros lieder españoles, también sacados de la colección del Spanisches Liederbuch, como el romance de Góngora "La más bella niña», ahora convertido en "Das reizendste Mädchen", uno de los Zwölf Lieder (op. 111, 1861). También puso música a «Pensamientos me quitan» («Es rauben Gedanken»), otro poema que de la Floresta pasó al Spanisches Liederbuch y fue traducido por Heyse. Este tipo de canciones romanceriles en el que una voz se queja a la madre fue especialmente atractivo a los compositores de lieder, especialmente si, como en este caso, usaban un estribillo que se alternaba con los episodios estróficos hasta llegar, a través del crecendo, a un momento de intensidad emocional y musical, que concluye con las cadencias de cierre. ${ }^{44}$

Lachner tiene también dos ciclos españoles de canciones religiosas traducidas por Melchior von Diepenbrock: Drei Marialieder aus M. Diepenbrock's geistlichem Blumenstraußy Fünf christliche Lieder aus M. Diepenbrock's geistlichem Blumenstrauß (ambos publicados en Stuttgart, Verein für Katholische Kirchenmusik, ca. 1850). La colección de Diepenbrock, Geistlicher Blumenstrauß aus spanischen und deutschen Dichtergärten (Regensburg, 1829), antología de poemas españoles del Siglo de Oro, es menos conocida hoy que la de Geibel o que el Spanisches Liederbuch, pero en su época sirvió también para un amplio repertorio de lieder románticos. Se limita a poemas de tema religioso, como indica su título (que traducido sería: Florilegio sagrado recogido del jardín poético español y alemán), correspondiendo con la carrera eclesiástica del compilador y traductor que, aconsejado por su amigo Clemens Brentano (del que tal vez también le

43. Sleeman y Davies (1982: 190).

44. Sleeman y Davies (1982: 183-185). 
vino la afición a la literatura española), siguió estudios teológicos y llegaría a ser cardenal. ${ }^{45}$ Diepenbrock contribuyó, como Geibel, a templar el imaginario español y asimilarlo a los valores cristianos y tradicionalistas heredados de la segunda escuela romántica. Su colección tuvo varias reediciones y se vio ampliada en 1852 con el título Geistlicher Blumenstrauß aus christlichen Dichter-Gärten den Freunden heiliger Poesie dargeboten (Sulzbach, 1852), cuya amplia difusión —Diepenbrock ha sido ya nombrado cardenal en 1850 — coincide con el gran momento de renovación del lied entre los seguidores de Schumann y con un segundo periodo de intenso interés por lo español (en 1856 saldría en Berlín la Primavera y Flor de Romances de Wolf y Hofmann, y cuatro años después, en Stuttgart, el Romanzero der Spanier und Portugiesen de Schack). El espíritu de la colección armoniza con el sentimiento conservador que a mediados de siglo tiende en Centroeuropa hacia una religiosidad íntima, doméstica y popular que se considera típicamente espańola (no puede olvidarse que el autor -o autora- española más traducido y difundido entonces, particularmente en lengua alemana, era Fernán Caballero, gran propagandista de esta visión de España). Muchos de los poemas traducidos en el florilegio sagrado se difundieron en revistas, almanaques devotos y otros repertorios populares. Así ocurrió con la traducción del poema de Lope de Vega «Pues que andáis en las palmas» («Die ihr dort wallet unter den Palmen, heilige Engel!»), que tras un recorrido exitoso en este tipo de publicaciones, tuvo versiones musicales de Friedrich Hieronymus Truhn («Die ihr dort wallet», 1843), Eduard Lassen ("Wiegenlied der Jungfrau Maria», op. 48, 1873), Felix von Woyrsch (en su ciclo español Spanisches Liederbuch, op. 14, 1887), Anton Urspruch («Der Maria Wiegenlied», op. 27, ca. 1893) y Joseph Schmid («Wiegenlied», 1899). 46

Sin embargo, el más famoso lied sobre el poema de Lope es el de Johannes Brahms, que prefirió la traducción de Emanuel Geibel («Die ihr schwebet / um diese Palmen») para su "Geistliches Wiegenlied» (op. 91/2, 1868), compuesto para saludar el embarazo de Amalie Schneeweiß, cantante y esposa de su amigo Joseph Joachim. La pieza es especialmente interesante, pues Brahms llega en ella a la absoluta apropiación de la tradición poética española al integrar el texto de Lope con la melodía de un villancico popular alemán interpretado por la viola,

45. En varias biografías se anota como primera edición la de 1826, pero no consta hoy en ningún catálogo. El que en alguna de sus traducciones publicadas en la revista Eos en 1828 señale que son pruebas para una colección que pretende publicar próximamente ( $A$ Als Probe einer nächstens erscheinenden Sammlung»), hace pensar que nunca existió esa primera edición de 1826, sino que la de 1829 fue la primera. El volumen incluye también su traducción alemana de La vida es sueño (Das Leben ein Traum): Ein allegorisch-religiöses Festspiel von Calderón de la Barca.

46. La traducción de Diepenbrock del poema de Lope se publicó por ejemplo en el periódico popular Der Erzähler: ein Unterhaltungsblatt für Jedermann, no 100, (December, 1838), que remite a la colección de Jesus Christus in seiner Ankunft, Kindheit und Jugend auf Erden, Augsburg, Karl Kollmann, 1837. 
que hace la segunda voz. Otro de los más conocidos y mejores lieder de Brahms sobre textos españoles es el «Spanisches Lied» (Sechs Gesänge, op. 6/1, 1852) sobre la traducción de Heyse de un anónimo español recogido en la Floresta de Böhl: «A la sombra de mis cabellos / mi querido se adurmió: / ¿si le recordaré ó no?», que traducida en «In dem Schatten meiner Locken» fue musicalizado, además de por Jensen y Brahms, por Johannes Schulze, Hugo Wolf, Josef Giehrl, Arno Kleffel, August von Othegraven, Felix von Woyrsch y otros. La versión de Brahms para soprano busca trasladar la emoción al tiempo delicada y apasionada de la amante, pero sin entregarse al exotismo. En la «Serenade», último lied de la serie Acht Lieder und Gesänge (op. 58) sí busca Brahms el aire español en la imitación de la guitarra en staccato, pero combinándola con las refinadas alusiones musicales de carácter descriptivo, en las que escuchamos la fuente, el susurro de la brisa o el caer de las gotas de agua. Sin embargo, en este caso el texto no es originalmente español, sino una imitación de la moda española realizada por el conde von Schack, uno de los grandes hispanistas alemanes de entonces.

De nuevo estamos, en el caso brahmsiano, ante un mestizaje interesante: el poema de Lope se integra con una melodía alemana, y el poema alemán de Schack, que imita las claves líricas españolas, se musicaliza con resonancias que pretenden recordar la guitarra.

Con Brahms llegamos al final del lied romántico alemán, aunque no del repertorio: en el fin de siglo otros autores seguirán componiendo sobre traducciones de poemas españoles, casi siempre a partir de las colecciones de Diepenbrock, Geibel y Heyse. Entre ellos tienen ciclos españoles Carl Joseph Brambach (Sechs Lieder aus dem Spanischen von Geibel und Heyse, 1871), Friedrich August Naubert (Spanische Liebeslieder aus dem Liederbuche vom Geibel und Heyse, 1876), Heinrich Molbe (pseudónimo de Heinrich von Bach, Sechs Lieder aus dem Spanischen von Geibel, 1878), Felix von Woyrsch (Spanisches Liederbuch, 1887) y especialmente Hugo Wolf cuyo Spanisches Liederbuch (1891) contiene cuarenta y cuatro piezas sacadas de la antología de Geibel y Heyse en las que la imagen musical de lo español vive una revitalización muy importante. Pero el último tercio de siglo requeriría un segundo estudio que escapa a los propósitos de este trabajo.

\section{Conclusiones}

El recorrido que ha podido hacerse en estas páginas puede bastar para obtener algunas conclusiones sobre la recepción de la tradición lírica española en el repertorio del lied alemán romántico. La primera, que estamos ante un campo de investigación extraordinariamente amplio y rico, necesitado de estudios que revisen el papel de antologías y colecciones de poemas españoles de gran difusión en su época y los modos de transmisión textual que escapan a los cauces habituales. En segundo lugar, ha podido observarse una evolución del lied que acompaña la recepción de la materia lírica española: las primeras versiones, como las de Corona Schröter, no intentan acompañar los textos de una melodía «a la 
española». Después, con el pleno advenimiento musical romántico, lo español se convierte en marca de renovación y revolución, hasta el punto de que Beethoven no solo respeta la lengua original, sino que traslada musicalmente los vigorosos ritmos populares ibéricos. La moda hispánica va generando unas claves líricas con apariencia «española» que se aprovechan como tales para unas piezas musicales que a su vez pretenden parecerlo, sin tener propiamente originales en nuestra poesía. Así ocurrió hasta la llegada de las traducciones de Diepenbrock y especialmente de Geibel y Heyse, que propiciaron una extraordinaria difusión de la Floresta de Böhl en versión alemana. El nuevo espíritu conservador de la Europa posromántica tiñe el imaginario español de una melancolía ya visible en los repertorios de lieder. En las versiones musicales que se hicieron a partir de estas traducciones, el lied ha dejado de ser revolucionario para convertirse en un género burgués, al tiempo que la imagen de España (aún asociada a la sencillez popular) sirve de asiento a los ideales conservadores de pureza e inocencia en los que ha concluido la exitosa asociación de Herder y Schlegel: España es un país de música, donde el canto forma parte de la cultura íntima del pueblo. Es la visión que traslada un repertorio de textos que escoge sobre todo las obras de la tradición popular, ya que para el efecto musical es fundamental la repetición y el paralelismo (marcas propias de los textos de tradición oral y bases estructurales del lied romántico). ${ }^{47}$ Así pues, la mayoría de los textos líricos que acompañaron a aquella música fueron populares o emparentados con esa tradición, como en los casos de Góngora, Castillejo, Lope o el portugués Gil Vicente.

En los lieder románticos los textos españoles adaptan sus matrices rítmicas y métricas a melodías nuevas, mientras se ajustan a una imagen de Espańa que va conformándose musicalmente. Porque si bien se puede afirmar con Vega Cernuda que la música es "mediadora mucho más rápida y fácil que la literatura», cabe matizar sus conclusiones sobre la dependencia que tiene de «fuentes literarias o textuales previas» para crear un imaginario. ${ }^{48} \mathrm{El}$ recorrido realizado demuestra cómo un mismo texto literario cobra significación muy diferente según las distintas musicalizaciones: de trasmitir una imagen bizarra, de fuerte colorido y tonalidades intensas, puede pasar a convertirse en algo íntimo y delicado, melancólico. La música, más que los textos, contribuyó a la evolución de la imagen de España: Schumann o Brahms introdujeron en el perfil español su propia manera de entenderlo, y también su propia personalidad. Los spanische lieder nos colocan ante un singular proceso de aculturación: la tradición de la lírica popular española se proyecta en un nuevo entorno artístico y estético hasta mimetizarse. El mestizaje más complejo es alcanzado gracias a la música.

47. Fehn y Thym (2010: 221).

48. Piensa que «[r]ara vez una ópera o un poema sinfónico ha creado una imagen del mundo $[\ldots]$ sin ayuda de la palabra. [...] Por eso la música no ha aportado rasgos nuevos al perfil de nuestro país». Vega Cernuda (1999: 365-366). 


\section{Bibliografía}

AlCalde, Pedro, «Introducción» a Ludwig van Beethoven, Cancións ibéricas, A Coruña, Viso, 1997, 1-2.

Aristegui, Constantino y Wolfgang Seibold, "Las «Canciones Españolas» de Schumann en recuerdo del 125 aniversario de la muerte». Ritmo, 51, 513 (1981), 10-19. <http://musinfo.de/index.php/Las_Canciones_ Espa\%C3\%B1olas_de_Schumann>

Bingham, Ruth, "The early nineteenth-century song cycle», The Cambridge companion to the Lied, James Parsons ed., Cambridge, Cambridge University Press, 2004, 101-119.

Böhl De Faber, Juan Nicolás, Floresta de rimas antiguas castellanas, Molina Huete, Belén (coord.), J. J. Labrador Herraiz (ed.), México, Frente de Afirmación Hispanista, 2015.

Briesemeister, Dietrich, Spanien aus deutscher Sicht: Deutsch-spanische Kulturbeziehungen gestern und heute, Tübingen, Max Niemeyer, 2004.

Brinkmann Scheining, Beatriz, Spanische Romanzen in der Übersetzung von Diez, Geibel und von Schack. Analyse und Vergleich, Marburg, Elwert, 1975.

Carreira, Xoán M., "Introducción General», Ciclo Remembranzas de España, Madrid, Fundación Juan March, 1998. <https://recursos.march.es/culturales/documentos/conciertos/cc67.pdf?v=22893902>

Comellas, Mercedes, "Tras los límites del lenguaje: las fuentes de la poética musical becqueriana», El Gnomo, 9 (2000), 25-48. <https://idus.us.es/ xmlui/handle/11441/43341>

De Persia, Jorge, «Distintas aproximaciones al estudio del hecho musical en España durante el siglo XIX», Revista de Musicología, 14, 1/2, (1991), 307-323.

Demmler, Martin, Robert Schumann und die musikalische Romantik, Mannheim, Artemis \& Winkler, 2010.

Diepenbrock, Melchior von, Geistlicher Blumenstrauß aus spanischen und deutschen Dichtergärten, Sulzbach, Seidel, 1829. <http://reader.digitalesammlungen.de/de/fs1/object/display/bsb10261846_00005.html>

Dillon, John Talbot, Letters from an English traveller in Spain, in 1778, on the Origin and Progress of Poetry in that Kingdom, Londres, Baldwin, 1781.

EICHENDORFF, Joseph von, Sämtliche Werke des Freiherrn Joseph von Eichendorff. Historisch-kritische Ausgabe, Stuttgart-Berlín-Colonia, Kohlhammer, 1993. $<$ https://archive.org/details/ha2smtlichewer01eich>

Einstein, Alfred, La música en la época romántica, Madrid, Alianza, 1986.

Fenn, Ann C. y Jürgen Thyм, «Repetition as Structure in the German Lied. The Ghazal", Of Poetry and Song: Approaches to the Nineteenth-century Lied, Jürgen Thym ed., New York, University Rochester Press, 2010, 220-239.

Fernández SAN EMETERio, Gerardo, «La pervivencia de la poesía española medieval y de los Siglos de Oro en la poesía alemana del siglo XIX», Dicenda 15 (1997), 203-217. 
-, "Canciones líricas españolas del Siglo de Oro y versiones musicales de Robert Schumann: El Spanisches Liederspiel y las Spanische Liebeslieden,, eHumanista: Journal of Iberian Studies, 5 (2005), 187-194. <https://es.scribd. $\mathrm{com} /$ document/24524809/Canciones-liricas-espanolas-del-Siglo-de-Oro-yversiones-musicales-de-Robert-Schumann-El-Spanisches-Liederspiel-y-lasSpanische-Liebeslieder>

García-Matós, M. Carmen, "Un folklorista del siglo xviII: "Don Preciso"», Revista de Musicología, 4, 2 (julio-diciembre 1981), 295-307.

Geibel, Emanuel, Volkslieder und Romanzen der Spanier, Berlin, Duncker, 1843. $<$ https://archive.org/details/bub_gb_7KUKAQAAMAAJ>

Geibel, Emanuel y Paul Heyse, Spanisches Liederbuch, Berlin, Besser, 1852.

Herder, Johann Gottfried, Über die neuere deutsche Literatur, Riga, Hartknoch, 1767. <http://www.deutschestextarchiv.de/book/show/herder_ litteratur01_1767>

-, Abhandlung über den Ursprung der Sprache, Berlin, Christian Friedrich Voß, 1770. <http://gutenberg.spiegel.de/buch/-2013/1>

—, Volkslieder, Leipzig, Weygand, 1778. <https://books.google.es/books/about/ Volkslieder.html?id=D5Y6AAAAcAAJ\&redir_esc=y >

Iza Zamácola, Juan Antonio [Don Preciso], Colección de las mejores Coplas de Seguidillas, Tiranas y Polos, que se han compuesto para cantar a la guitarra con un discurso sobre las causas de la corrupción y abatimiento de la música Española, Madrid, Villalpando, 1799. <https://reader.digitale-sammlungen.de/de/fs1/ object/display/bsb10607790_00005.html>

Kanowsky, Walter, «Heine als Benutzer der Bibliotheken in Bonn und Göttingen», Heine-Jahrbuch, 12 (1973), 129-153.

KanT, Immanuel, Observaciones acerca del sentimiento de lo bello y de lo sublime, introducción, traducción y notas de Luis Jiménez Moreno, Madrid, Alianza, 1990.

Lyte, Herbert O., Spanish Literature and Spain in some of the leading German Magazines of the second half of the Eighteenth Century, Madison, University of Wisconsin, 1932.

Molina Huete, Belén, «La Floresta de rimas antiguas castellanas de Böhl de Faber: proyecto antológico y canon romántico», Gramática, canon e historia literaria: estudios de Filología española entre 1750 y 1850, Victoriano Gaviño Rodríguez, Fernando Durán López coord., 2010, 289-326.

Muñoz Martínez, Manuela, Los ciclos españoles de Robert Schumann: Spanisches Liederspiel, opus 74 y Spanische Liebeslieder, opus 138, Tesis Doctoral, Universitat de Valencia, 2015. < roderic.uv.es/handle/10550/50643>

Myers Brown, Sandra, «El Volksgeist herdiano y expresiones románticas de "lo español". Estudios de los Spanische Lieden,, Musicología global, musicología local, Javier Marín López ed., Madrid, Sociedad Española de Musicología, 2013, 1273-1290.

Parakilas, James, «How Spain got a soul», The exotic in Western music, Jonathan Bellman ed., Boston, Northeastern University Press, 1998, 137-193. 
Romero, Leonardo, «La visión del Volkgeist en la crítica de los románticos españoles», Individuo y sociedad en la literatura del XIX, Raquel Gutiérrez y Borja Rodríguez eds., Santander, Tremontorio, 2012, 11-20.

Schlegel, Friedrich, Kritische Friedrich Schlegel Ausgabe, Munich-Paderborn, Schöningh, 1962.

SchöNING, Udo, «Scherrs Romania. Bemerkungen zum romanischen Anteil im Bildersaal der Weltliteratur", Weltliteratur in deutschen Versanthologien des 19. Jahrhunderts, Helga E/mann, Udo Schöning eds., Berlin, Erich Schmidt, 1996, 410-432.

Sleeman, Margaret G. y Gareth A. Davies, Variations on Spanish themes: the Spanisches Liederbuch of Emanuel Geibel and Paul Heyse and its reflection in the songs of Hugo Wolf, Leeds, Proceedings of the Leed Pilosophical and Literary Society, 8, 1982, 155-274.

Steinig, Martina, "Wo man singt, da lass' dich rubig nieder...": Lied-und Gedichteinlagen im Roman der Romantik, Berlin, Frank \& Timme, 2006.

Vega Cernuda, Miguel Ángel, «La imagen de España en la música no española», Nassarre: Revista aragonesa de musicología XV, 1-2 (1999), 315-366. 